\title{
Acellular Cadaveric Dermal Matrix
}

National Cancer Institute

\section{Source}

National Cancer Institute. Acellular Cadaveric Dermal Matrix. NCI Thesaurus. Code C82364.

A human dermis-derived allograft material. Acellular cadaveric dermal matrix (ACDM) is derived from human cadaveric dermis from which the epidermis, all viable cells and major histocompatibility class (MHC) II antigens have been removed to minimize alloimmunogenicity, while the dermal collagen matrix is preserved. ACDM may placed over wounds to aid as a substitute for skin when necessary such as for surgical reconstruction or for protection against wound exposure and breakdown and wound infection. 